\title{
Quality of Mobile Apps for Language Learning
}

\author{
Sergei Kruchinin*, and Ekaterina Bagrova \\ Industrial University of Tyumen, 629810 Noyabrsk, Russia
}

\begin{abstract}
Mobile apps are new format of learning foreign languages. They are great as an additional way of learning, but cannot be a substitute for ordinary learning. Each app provides its own way of learning a foreign language. Each of them has its own pros and cons, and none of them is the best one. A combination of several apps is more efficient than using just one of them. However, all of them are dedicated to learning a language instead of practicing a language. Therefore, tutors, educational groups, and other regular forms of education cannot be fully substituted by mobile apps for language learning.
\end{abstract}

\section{Introduction}

Knowledge of foreign languages is an indisputable plus for career advancement. But not everyone can set aside a few days a week for serious language learning. To help those who are very busy, mobile apps that allow you to learn at any convenient time and in any place have appeared.

The modern world is a world after globalization [1]. This means that communication between people from different countries is at a fundamentally different level at the moment. It is absolutely normal for us to change our country of residence, study abroad, communicate with foreigners and use foreign languages for business communication. In fact, not knowing at least one foreign language in the modern world makes a person excluded from many areas of life [2].

At the moment, perhaps, the main foreign language is English. However, it is not possible to limit oneself to them in connection with the development of China and Latin America.

In fact, the modern world creates conditions where a foreign language is extremely necessary and necessary in everyday life, and on the other hand, the level of globalization is not high enough for constant communication in this language from the external environment [3]. This situation creates a demand for mobile applications to maintain their language level in conditions when there is no opportunity or need to study with a teacher. In addition, many modern people have been living in the information society since childhood. It is much easier for them to interact with a computer than with other people. Mobile apps also help with this issue. These applications can be created directly by teachers, or they can use artificial intelligence to solve their internal tasks.

\footnotetext{
*Corresponding author: kruchinin.s.v@bk.ru
} 
Thus, the demand for mobile applications for learning foreign languages is formed by students who want to start learning a language, continue or maintain the necessary level. At the same time, the development of technologies makes it possible to form these systems both on the basis of well-known methods and materials, and on the basis of information technologies [4]. At the same time, the question of quality and how to determine it remains open.

\section{Methods}

The article examines the advantages and disadvantages of modern mobile applications for learning foreign languages. To do this, we analyzed the largest applications of the Play Market and AppStore for learning foreign languages, studied their features, functionality and business models behind it. As a result, their quality was evaluated, as well as the possibility of practical use without a teacher.

\section{Results}

\subsection{LinguaLeo}

Despite its image as a service for those who are just starting to learn English, LinguaLeo offers a wide range of opportunities for those who have already mastered the language of Shakespeare, Hemingway, and Steve Jobs. Entrepreneurs will probably be interested in the built-in "Business English", which contains an intensive grammar course, a course on business correspondence, and materials on business, accounting and finance.

Among the 20 courses designed for students of different levels, there are simulators for CAE, FCE, IELTS General, IELTS Academic, and GIA tests. To make the learning process more interesting and exciting, LinguaLeo offers different types of exercises: six types of interactive training, a personal dictionary with transcriptions and voice-over, thematic dictionaries, a large offline dictionary of 60,000 words, a selection of English texts for every taste (including TED and a collection from the British Council), as well as the ability to study without an Internet connection.

\subsection{Duolingo}

In 2013, Duolingo was twice named "best educational app". At first, the service received a high rating from Apple, and later confirmed its status in Google Play, when the number of downloads exceeded one million in the first three weeks after the release. The Russian version offers only two languages to learn: English and German. However, if you choose English as the base language, the number of available languages will increase to six.

Each section consists of several lessons, including learning new words, listening, grammar, reading, spelling, pronunciation, and two-way translation exercises. If you practice regularly, the result will not be long in coming. The training scheme looks like a kind of tree of achievements, so you can't skip one topic and immediately take up another.

Duolingo helps you expand your vocabulary, master grammatical constructions, and make sure you have good pronunciation. The app uses its own currency - lots that can't be bought, but can only be earned by hard work. 


\subsection{British Council}

In addition to sharing cultural values, one of the main tasks of the British Council is to help you learn English. For those who do not have time to go to courses and study with a teacher, there is an impressive selection of 13 mobile applications. The British Council recommends learning the language through games, podcasts, movies, and quizzes.

Learn English Grammar is an Interactive grammar book designed for different levels of English proficiency: from beginner to advanced. IELTS Wordpower contains more than 100 questions in 11 categories and helps you prepare for the exam.

My Word Book offers to expand your vocabulary with the help of didactic cards, which you can fill with your own words, notes, and pictures that facilitate the learning process.

Learn English Audio \& Video lessons, which include an audio script and comprehension exercises to train your listening skills.

For football fans, a special Premier Skills app is provided.

\subsection{Babbel}

Babbel has an audience of more than 15 million users, including important figures such as German Chancellor Angela Merkel. You can learn 14 languages using this service: English, German, Spanish, Italian, French, Portuguese, Swedish, Turkish, Dutch, Polish, Indonesian, Norwegian, Danish, and Russian.

Some of the content is available without payment, but full access requires a monthly fee depending on the selected package.

Each lesson focuses on both vocabulary and grammar. The exercises include building dialogues with a subscript translation into English (Babbel is not yet Russified), which allows you to learn words and language constructions simultaneously.

The app is voiced by two voices, male and female, which brings variety to the learning process.

The language course contains several levels for beginners and advanced students, thematic collections of vocabulary, grammar, pronunciation, a section about the cultural traditions of the country, and additional materials that allow you to learn more about idioms and false friends of the translator.

\subsection{Busuu}

Busuu is not just a language learning service, but a whole community of people who help each other acquire new knowledge and master English, German, French, Italian, Spanish, Portuguese, Russian, Polish, Turkish, Arabic, Japanese, and Chinese.

Free membership includes vocabulary, reading and writing exercises, as well as interactive exams. A premium subscription offers access to grammar lessons, audio recordings, video tutorials, special training for travel, discounts on business courses, and unlimited access to all materials for learning various foreign languages.

Each language course is divided into levels: elementary, elementary, intermediate, and higher. Each of them includes several lessons, during which the user is asked to learn words, read and listen to the text, answer questions, and then complete a small written task.

The undoubted advantage of Busuu is the ability to communicate with native speakers, who will help you adjust your knowledge and raise it to a new level. 


\subsection{Memrise}

Memrise is not just a language learning service. In addition, the site offers courses on various topics: art and literature, mathematics and science, memory training, profession and career, and many others. Memrise is hardly a classic learning app; rather, it is a collection of courses for all occasions. For example, in the English category, you can find grammar tests, collections of irregular verbs, phrasal verbs, and even novels by Charles Dickens.

To make it easier to remember, the service offers various mnemonic rules and unforgettable illustrations. The interface deserves special mention. Developers compare the learning process to growing flowers in a garden - it's not enough just to scatter some seeds in the ground (learn a word). From time to time, they need to be watered (refreshed) so that they do not "wither" in the memory.

\subsection{FunEasyLearn}

For those who have already learned the basics of grammar, but want to expand their vocabulary, we recommend FunEasyLearn. The app does not have a stylish design and only works with Android, but the study method is definitely worthy of the highest rating. To help you remember 6,000 words (this is how much each course contains), 7 types of different exercises have been developed that use different learning mechanisms.

Currently, there are 17 languages available in Google Play and on the site: English, German, Spanish, Italian, Polish, French, and Chinese have already been adapted for Russian users. Korean, Turkish, Ukrainian, Danish, Greek, Indonesian, Swedish, Thai and Czech are easy to learn for those who already know English.

\subsection{Language learning apps pros and cons}

First of all, let's look at the advantages and disadvantages of using artificial intelligence in mobile applications for learning foreign languages. The main advantages include [5]:

- ease of detecting repeated errors;

- no need to interact with another person, which means freedom of action in time and space;

- continuous improvements of the system;

- analysis of the user's activity and language skills in various areas, drawing conclusions based on the collected data;

- a wide range of applications that can be combined with each other.

In fact, all these advantages are only significant if the application is initially of high quality. First of all, the main criterion for the quality of a mobile application for learning languages is the accuracy of the information and responses provided by it. In fact, we need a high-quality database of foreign languages in order to train artificial intelligence [6].

Second, the app must be intuitive, have a high-quality internal learning system, and engage the user. We are talking about gamification, and about certain formal things such as the certificates. It is important for the user not only to learn the language, but also to do it fun, while achieving their goals [7].

Third, the training system itself must take into account the features of the user's learning ability. For example, you can't just learn words without using them later. At the same time, you cannot let the user go through all the exercises with these words at once. It is necessary to return it to these words with a certain frequency, including blocking the functions of further learning without timely repetition. The same applies to grammar and other aspects of the language [8]. 
Turning to the disadvantages of using artificial intelligence, we can simply say that at the moment it is very far from human capabilities, which implies its constant training, as well as support for users by other people.

Returning directly to mobile applications for learning foreign languages, we can say with confidence that none of them meets all the quality criteria at the moment. However, their combination will allow you to develop knowledge of a foreign language, as well as skills in its use to a sufficiently high level. At the same time, even a set of applications cannot develop in a person the personal qualities necessary for learning. Thus, we can say that at the moment the main obstacle to learning foreign languages through applications is a feature of the human psyche. That is why you should Supplement the app with classes with a teacher who has not only expert knowledge, but also the right temperament for you.

\section{Discussion and Conclusion}

Mobile apps are good for language learning. They are great as an additional instrument for language learning. If you already know the basics of a language [2], they can be extremely helpful; especially, for reading or learning grammar. They are not the best method for practicing oral or writing language skills [4]. Moreover, a combination of several apps is more efficient than usage of any specific one. Their prices are reasonable. However, some of them, such as LinguaLeo, are more affordable than others (Busuu, for example).

The most significant issue is not just learning languages, as suggested by the apps [6] it is language practice. All of the apps mentioned allow users to only practice language in very restrictive ways [7, 8]. Therefore, any learning with the help of apps should be expanded by language practice either with a tutor, educational groups or through the use of proofreading services for writing practice.

\section{References}

1. R. Godwin-Jones, Language Learning \& Technology, 15, 2 (2011)

2. G. Stockwell, Calico J., 30, 118 (2013)

3. R. Gangaiamaran, M. Pasupathi, Int. J.of Applied Engineering Research, 12, 11242 (2017)

4. B. Klimova, Education and Information Technologies, 23, 1091 (2018)

5. X. Chen, J. of Educational Tech. Development and Exchange, 9, 3 (2016)

6. N. Gamlo, English Language Teaching, 12, 49 (2019)

7. K. G. Erdyneeva, Int. Review of Management and Marketing, 6, 29 (2016).

8. R. A. Madani, Higher Education Studies, 9, 100 (2019) 